\title{
Vision for life sciences: interfaces between nanoelectronic and biological systems
}

\author{
Madkour LH* \\ Department of Chemistry, Faculty of Science, Baljarashi, Al Baha University, Al Baha, Saudi Arabia
}

Nanomedicine is the application of nanotechnology (the engineering of tiny machines) to the prevention and treatment of disease in the human body. Nanomaterials can impart antibacterial and anti-odour functionality on human skin in powder, gel, stick or spray underarm products. It has also antimicrobial and anti-irritant properties. This discipline is in its infancy. It has the potential to change medical science dramatically in the 21 st century.

\section{Molecular biomimetics: Nanotechnology through biology}

Molecular biomimetics. This is the marriage of materials science engineering and molecular biology for development of functional hybrid systems, composed of inorganics and inorganic-binding proteins. The new approach takes advantage of DNA-based design, recognition, and self-assembly characteristics of biomolecules.

Traditional materials science engineering produces materials (for example, mediumcarbon steels depicted in the bright- and darkfield TEM images), that have been successfully used over the last century. Molecular biology focuses on structure- function relations in biomacromolecules, for example, proteins.

In molecular biomimetics, a marriage of the physical and biological fields, hybrid materials could potentially be assembled from the molecular level using the recognition properties of proteins under the premise that inorganic surface-specific polypeptides could be used as binding agents to control the organization and specific functions of materials.Molecular biomimetics simultaneously offers three solutions to the development of heterofunctional nanostructures.

(1) The first is that protein templates are designed at the molecular level through

genetics. This ensures complete control over the molecular structure of the protein template (that is, DNA-based technology).

(2) The second is that surface-specific proteins can be used as linkers to bind synthetic entities, including nanoparticles, functional polymers, or other nanostructures onto molecular templates (molecular and nanoscale recognition).

(3) The third solution harnesses the ability of biological molecules to self- and coassemble into ordered nanostructures. This ensures a robust assembly process for achieving complex nano-, and possibly hierarchical structures, similar to those found in nature (self-assembly).

The current knowledge of protein-folding predictions and surfacebinding chemistries does not provide sufficiently detailed information to perform rational design of proteins. To circumvent this problem, massive libraries of randomly generated peptides can be screened for binding activity to inorganic surfaces using phage and cellsurface display techniques. It may ultimately be possible to construct a'molecular erector' set, in which different types of proteins, each designed to bind to a specific inorganic surface, could assemble into intricate, hybrid structures composed of inorganics and proteins. This would be a significant leap towards realizing molecularly designed, genetically engineered technological materials.

\section{Selection of inorganic-binding proteins through display technologies}

There are several possible ways of obtaining polypeptide sequences with specific affinity to inorganics. A number of proteins may fortuitously bind to inorganics, although they are rarely tested for this purpose. Inorganic-binding peptides may be designed using a theoretical molecular approach similar to that used for pharmaceutical drugs. This is currently impractical because it is time consuming and expensive. Another possibility would be to extract biomineralizing proteins from hard tissues followed by their isolation, purification and cloning. Several such proteins have been used as nucleators, growth modifiers, or enzymes in the synthesis of certain inorganics. One of the major limitations of this approach is that a given hard tissue usually contains many proteins, not just one, all differently active in biomineralization and each distributed spatially and temporally in complex ways.Furthermore, tissue-extracted proteins may only be used for the regeneration of the inorganics that they are originally associated with, and would be of limited practical use. The preferred route, therefore, is to use combinatorial biology techniques. Here, a large random library of peptides with the same number of amino acids, but of different sequences, is used to mine specific sequences that strongly bind to a chosen inorganic surface.

Since their inception, well-established in vivo combinatorial biology protocols (for example, phage display (PD) and cell-surface display (CSD)) have been used to identify biological ligands and to map the epitope (molecular recognition site) of antibodies. Libraries have also been screened for various biological activities, such as catalytic properties or altered affinity and specificity to target molecules in many applications including the design of new drugs, enzymes, antibodies, DNA-binding proteins and diagnostic agents. The power of display technologies relies on the fact that an a priori knowledge of the desired

Correspondence to: Loutfy H. Madkour, Department of Chemistry, Faculty of Science, Baljarashi, Al Baha University, Al Baha, Saudi Arabia, E-mail: loutfy_ madkour@yahoo.com

Received: February 07, 2017; Accepted: March 09, 2017; Published: March 11, 2017 
amino acid sequence is not necessary, as it can simply be selected and enriched if a large enough population of random sequences is available. In vitro methods, such as ribosomal and messenger RNA display technologies, have been developed for increased library size $\left(10^{15}\right)$ compared to those of in vivo systems $\left(10^{7-10}\right)$.

Combinatorial biology protocols can be followed in molecular biomimetics to select polypeptide sequences that preferentially bind to the surfaces of inorganic compounds chosen for their unique physical properties in nano- and biotechnology. Libraries are generated by inserting randomized oligonucleotides within certain genes encoded on phage genomes or on bacterial plasmids (step 1 in Figure 1).

This leads to the incorporation of a random polypeptide sequence within a protein residing on the surface of the organism (for example, the coat protein of a phage or an outer membrane or flagellar protein of a cell; step 2). The eventual result is that each phage or cell produces and displays a different, but random peptide (step 3). At this stage, a heterogeneous mixture of recombinant cells or phages are contactedwith the inorganic substrate (step 4). Several washing cycles of the phages or the cells eliminate non-binders by disrupting weak interactions with the substrate (step 5). Bound phages or cells are next eluted from the surfaces (step 6). In PD, the eluted phages are amplified by reinfecting the host (step 7). Similarly, in CSD, cells are allowed to grow (steps 7,8 ). This step completes a round of biopanning. Generally, three to five cycles of biopanning are repeated to enrich for tight binders. Finally, individual clones are sequenced (step 9) to obtain the amino acid sequence of the polypeptides binding to the target substrate material.

\section{(1) A Bio-Nanowire Device Interface (Figure 2)}

Because the sizes of biological macromolecules are comparable to nanowire building blocks, these structures represent natural transducers for ultra-sensitive detection.

(2) Nanowire Nanosensors: Beginning (Figure 3): Cui, Wei, Park \& Lieber: Science 293, 1289 (2001)

(3) Multiplexed Cancer Marker Detection (Figure 4): Zheng, Patolsky \& Lieber, Nat. Biotech. 23, 1294 (2005).

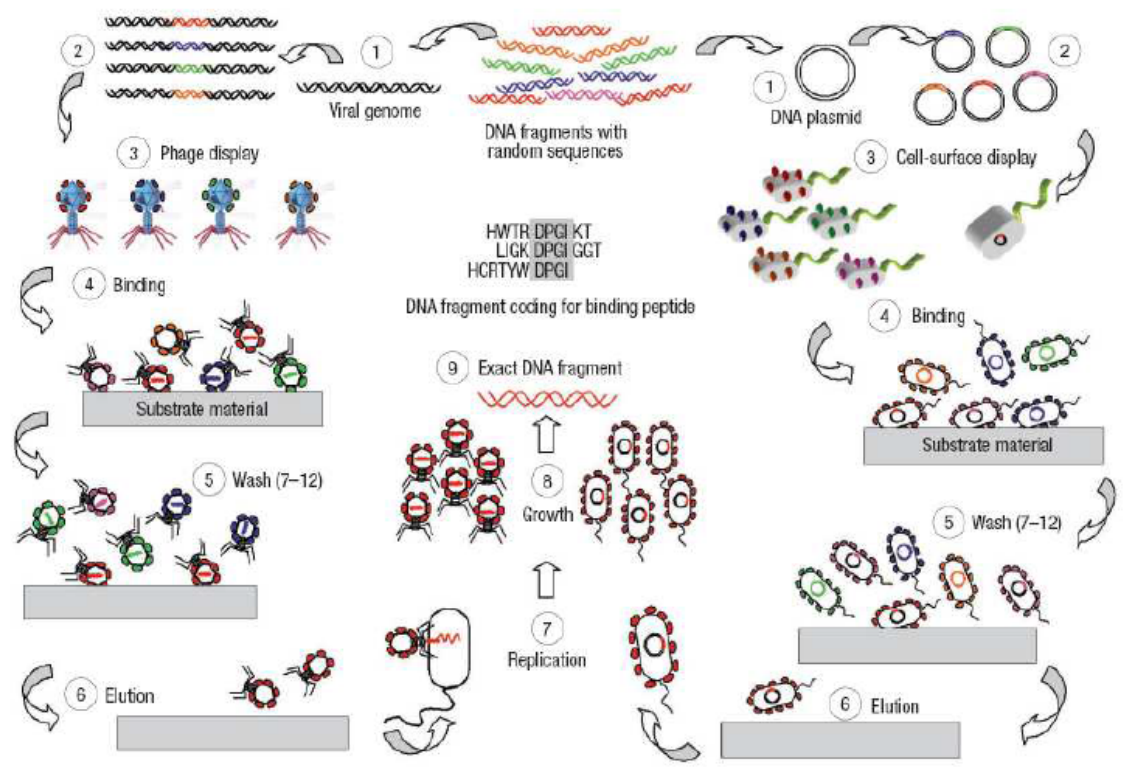

Figure 1. Phage display and cell-surface display. Principles of the protocols used for selecting polypeptide sequences that have binding affinity to given inorganic substrates. [Sarikaya, C. Tamerler, A.K.Y. Jen, K. Schulten F. Baneyx, Molecular biomimetics: nanotechnology through biology, Nature Materials, vol 2, 2003, p.p. 577-585].

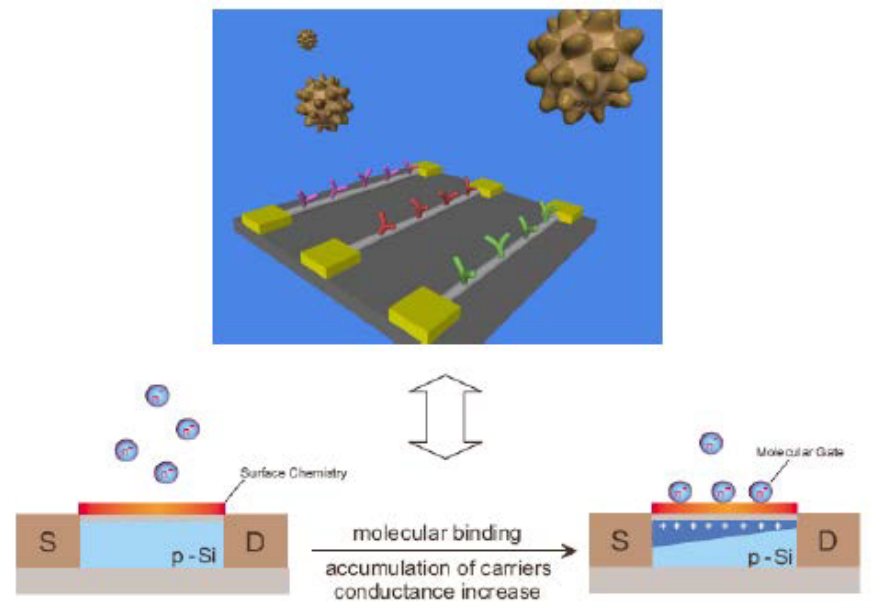

Figure 2. A Bio-Nanowire Device Interface. 

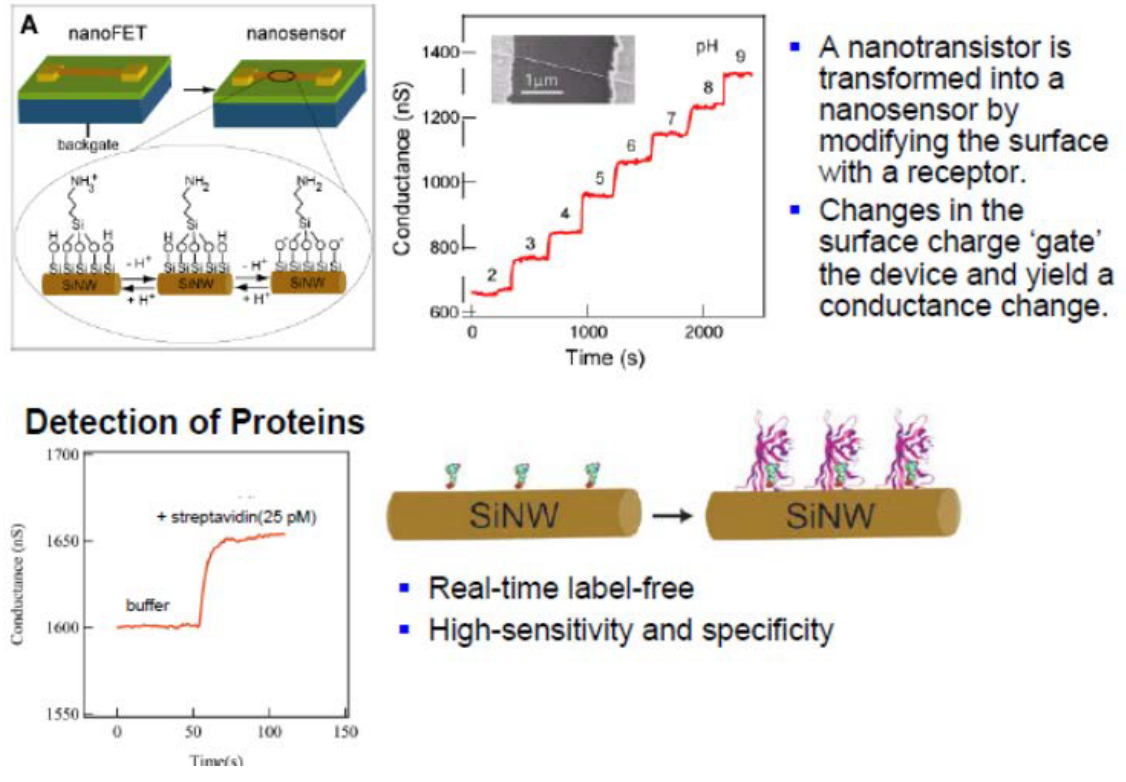

Figure 3. Nanowire Nanosensors: Beginning.
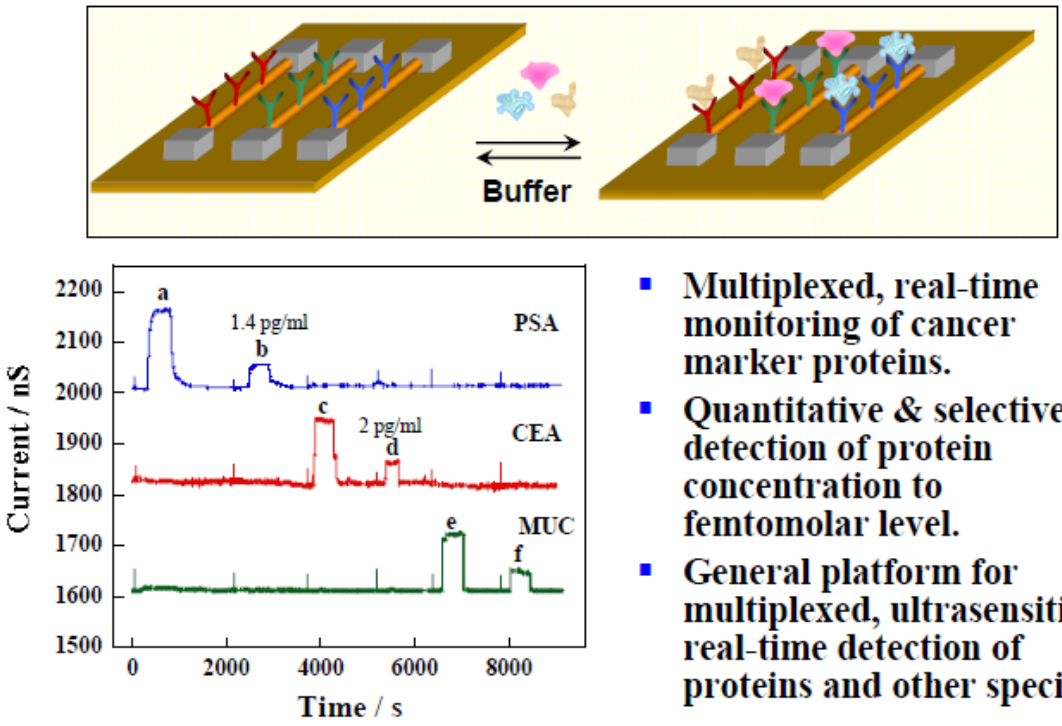

- Multiplexed, real-time monitoring of cancer marker proteins.

- Quantitative \& selective detection of protein concentration to femtomolar level.

- General platform for multiplexed, ultrasensitive, real-time detection of proteins and other species!

Figure 4. Multiplexed Cancer Marker Detection.

(4) Undiluted Blood Serum Analysis (Figure 5): Serum samples are characterized after single step 'desalting'purification. (1) Buffer; (2) Donkey Serum (DS), $59 \mathrm{mg} / \mathrm{ml}$ total protein; (3) DS + $2.5 \mathrm{pM}$ PSA; (4) DS + 25 pM PSA (1) DS + $0.9 \mathrm{pg} / \mathrm{ml}$; (2) DS. Marker proteins are detected selectively in presence of ca. 100-billion-fold excess of serum proteins.

(5) Nanoelectronic-Cell Interfaces (Figure 6):

Nanowire nanoelectronic devices can enable:

- Interface to cells at natural scale of biological communication

- Input/output of electrical signals

- Input/output of chemical/biological signals

\section{Conclusions}

Nanoelectronic-Biological Interfaces Enable:
- Diagnostic devices for disease detection

- General detection \& kinetics platform

- New tool for single-molecule detection/biophysic

- Powerful devices for electronic and chem/bio recording from cells, tissue \& organs

- Potential implants for highly functional \& powerful prosthetics, as well as hybrid biomaterials enabling new opportunities

Evaluating Research Motivation: Progress?

- Synthetic challenge of controlling structure and composition on many length scales

- $\quad$ Fundamental scientific questions in 1-dimensional systems

- Central importance of nanoscale wires in integrated nanosystems 

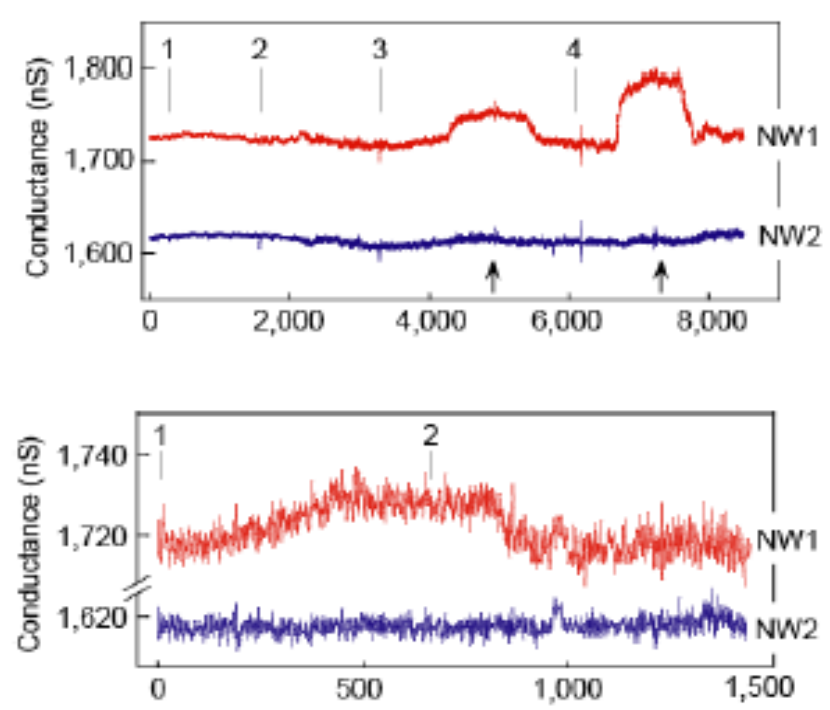

Figure 5. Marker proteins are detected selectively in presence of ca. 100-billion-fold excess of serum proteins.

\section{An example:}
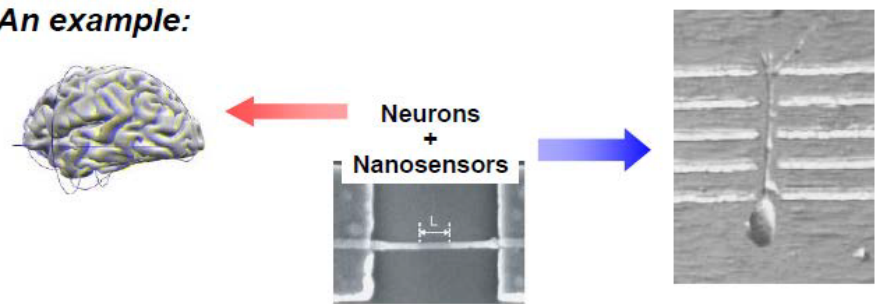

Figure 6. Nanoelectronic-Cell Interfaces.

- $\quad$ New/novel materials can make revolutionary vs. evolutionary changes in science and technology!

$\Rightarrow$ Many fundamental scientific questions remain, and will require bold researchers to address.

$\Rightarrow$ Pushing ourselves to identify and tackle these 'big' challenges, while difficult, offers the best opportunity to make revolutionary advances and benefit society!

\section{References}

1. Foundation CaDR (2010) One degree of separation: paralysis and spinal cord injury in the United States.

2. Singh A, Tetrault L, Kalsi-Ryan S, Nouri A, Fehlings MG (2014) Global prevalence and incidence of traumatic spinal cord injury. Clin Epidemiol 6: 209-331.

3. 22 September, 2016: "Global Hearts", a new initiative from the World Health Organization (WHO). New initiative launched to tackle cardiovascular disease, the world's number one killer. Cardiovascular disease. http://www.who.int/cardiovascular diseases/en/

4. WHO Media centre (2017) Cancer. http://www.who.int/mediacentre/factsheets/fs297/en/

5. http://www.cancerresearchuk.org/

6. Fujiwara A, Hoshino T, Westley JM (1985) Anthracycline antibiotics. Critical Reviews in Biotechnology. Anthracycline 3: 133.

7. Mele D, Nardozza M, Spallarossa P, Frassoldati A, Tocchetti CG, et al. (2016) Current views on anthracycline cardiotoxicity. Heart Fail Rev 21: 621-34.

8. Kucharska W, Negrusz-kawecka M, Gromkowska M (2012) Cardiotoxicity of oncological treatment in children. Adv Clin Exp Med 21: 281-288.

9. Hagen EM, Rekand T, Gronning M, Faerestrand S (2012) Cardiovascular complications of spinal cord injury. Tidsskr Nor Laegeforen 132: 1115-1120.

10. Kalisvaart JF, Katsumi HK, Ronningen LD, Hovey RM (2010) Bladder cancer in spinal cord injury patients. Spinal Cord 48: 257-261.

11. Kao CH, Sun LM, Chen YS, Lin CL, Weng MW (2016) Risk of Nongenitourinary Cancers in Patients With Spinal Cord Injury - A Population-based Cohort Study. Medicine 95: e2462.

12. Chen JJ, Wu PT, Middlekauff HR, Nguyen KL (2016) Aerobic Exercise in Anthracycline-Induced Cardiotoxicity: A Systematic Review of Current Evidence and Future Directions. Am J Physiol Heart Circ Physiol Dec 6: ahead of print.

13. Smith AE, Molton IR, Jensen MP (2016) Self-reported incidence and age of onset of chronic comorbid medical conditions in adults aging with long-term physical disability. Disabil Health J 9: 533-538.

14. Guertin PA, Ung RV, Rouleau P, Steuer I (2011) Effects on locomotion, muscle, bone, and blood induced by a combination therapy eliciting weight-bearing stepping in nonassisted spinal cord-transected mice. Neurorehabil Neural Repair 25: 234-242.

15. Radhakrishna M, Steuer I, Prince F, Roberts M, Mongeon D, et al. (2016) Double-blind, placebo-controlled, randomized phase I/IIa study (safety and efficacy) with buspirone/ levodopa/carbidopa (Spinalon) in subjects with complete AIS A or motor-complete AIS B spinal cord injury. Curr Pharm Des Dec 27. Ahead of print.

16. Hofstoetter US, Knikou M, Guertin PA, Minassian K (2016) Probing the Human Spina Locomotor Circuits by Phasic Step-Induced Feedback and by Tonic Electrical and Pharmacological Neuromodulation. Curr Pharm Des Dec 27. Ahead of print.

17. Henninger C, Fritz G (2017) Statins in anthracycline-induced cardiotoxicity: Rac and Rho, and the heartbreakers. Cell Death Dis 8: e2564.

Copyright: (C2017 Madkour LH. This is an open-access article distributed under the terms of the Creative Commons Attribution License, which permits unrestricted use, distribution, and reproduction in any medium, provided the original author and source are credited. 